\title{
Role of Translation in Comparative Literature
}

\section{Surjeet Singh Warwal}

\begin{abstract}
In today's world Translation is getting more and more popularity. Therearemanyreasons behind it. The firstand theforemost reason is that it contributes to the unity of nations. It also encourages mutual understanding, broad-mindedness, cultural dialogues and intertextuality. But one can hardly think of comparative literature without immediate thinking of translation. For instance most readers in India know the works of Goethe, Tolstoy, Balzac, Shakespeare and Gorky only through translation. It is through the intermediary of translator that we get access to other literatures.

Thus Comparative Literature and translation humanize relationship between people and nations. As an intermediary between languages, thoughts and cultures, they contribute to the respect of difference and alterability. Moreover, they unite the self and the other in their truths, myths, force and weakness. From a historical perspective, comparative literature and translation have always been complementary. Without the help of translation a normal person, who usually knows two to three languages would never have known the universal masterpieces of Dante, Shakespeare, Borges, Kalidas, and Cervantes etc. A normal person usually may not know more than two-three languages. But if s/he wanted to study and compare the literature of two or more languages s/he must be familiar with those languages and cultures. If s/he does not know any of these languages s/he can take help of translation. Those texts might be translated by someone else who knows that language and the comparativist can use that translated text to solve his/her purpose. So we can say that:
\end{abstract}

1. Both comparative literature and translation are inter-linked. 
2. A layman can come closer to the major writers of different fields.

3. Through the translation of literature from different languages we can understand their philosophy, sociology, psychology and above all their culture.

4. Either translation or through comparison the problems of particular area's people will be analyzed.

5. With the help of translation a text become able to get a wider range of readers.

Comparative literature is a discipline dedicated to the study of literature without national and linguistic barriers. The student of comparative literature studies problems in genre, mode, literary period or movement. The comparatists probe the mechanics of literary forms and engage themselves in the analysis of existing theoretical and critical approaches and the formulation of necessary critical distinctions of equal importance. The compartivist also deal with the questions of interaction between literature, other arts and disciplines. The compartivist may study the political, social and an intellectual context of literary emphasis is preserved. In other words, the main objective of the study of comparative literature is the proper appreciation of literature in a larger perspective, involving more than one literature and specially those growing across the national boundaries. In a multilingual country like ours we have two basic objectives for studying comparative literature.

No doubt the role of translation in comparative literature is very important. It becomes more valuable in today's world when the whole world has become a global village. With the advancement of technology people living in different countries with different languages come closer to each other. Although there is a one international language, English, which is the common source of communication between people but still there is a problem in the study of literature as literatures is usually written in regional languages or languages of that particular countries such as France's 
literature is in French and literature of Russia is in Russian language. It is not compulsory that every comparativist will know the all languages. So there is need of translation by which a comparativist can read and understand those literary works which are not in his/ her own language. With the help of translation we become familiar with the customs, dress code and culture of other countries.

In short it can be said that translation plays a great role in comparative literature. We can even say that comparative study of literatures from different languages, cultures and socio-cultural backgrounds is not possible. So translation occupies a special place in comparative literature. In this age of globalization comparative literature as a subject is getting more and more popularity. But there is no one who is perfect in all the languages. So translation has played a very important role to understand the literature \& culture of different languages without which we cannot do a comparative study of various literary works written in different languages. So Comparative literature is a tree with translation as its most important branch.

Comparative literature is a new discipline in our country which is fully grown in the academic fields of western World. Basically it is a method through which we study literature from the comparative point of view using comparison as a main tool of study. At the earlier stages although comparative study of literature was a part of general literary criticism but now a days it has become a separate discipline with all its implications. Now it becomes an aspect of literary criticism which aids our understanding and enjoyment of literature. Here literature is studied not in isolation but in comparison. Under this discipline we may compare two or more similar or even dissimilar forms or trends within the literature of the same language. It can be a comparison of two or more authors or two or more works in the same language. It may be a comparison of similar or dissimilar forms or trends of two or more languages of the same country like we can do a comparative study of Lyric in Punjabi, Hindi and Malayalam. It can also cut across the national boundaries 
and compare themes, literary forms of the authors of various languages of the world to discover the underlying elements of unity in diversity with a universal view of literature. In such a broad view literature is independent of linguistics, national and racial demarcations. So we can say that Comparative Literature is critical study dealing with literature of two or more different linguistics, cultural or national groups. It also include the range of inquiry and comparison of different types of art: for example a comparativist might investigate the relationship of film to literature, dance, music etc. it also include the comparison of literature with other disciplines like literature with history, sociology, psychology etc.

In today's world this subject is getting more and more popularity. There are many reasons behind it. The first and the foremost reason is that it contributes to the unity of nations. It also encourages mutual understanding, broad-mindedness, cultural dialogues and intertextuality. But one can hardly think of comparative literature without immediate thinking of translation. For instance most readers in India know the works of Goethe, Tolstoy, Balzac, Shakespear and Gorky only through translation. It is through the intermediary of translator that we get access to other literature.

Thus Comparative Literature and translation humanize relationship between people and nations. As an intermediary between languages, thoughts and cultures, they contribute to the respect of difference and alterability. Moreover, they unite the self and the other in their truths, myths, force and weakness. From a historical perspective, comparative literature and translation have always been complementary. Without the help of translation a normal person who usually know two or three languages would never have known the universal masterpieces of Dante, Shakespeare, Borges, Kalidas, Cervantes etc. it is only through translation we get access to the great literary works written in other languages which we can't read. Before discussing the relationship of translation we must know what is translation? 


\section{What is translation?}

Translation is the process in which a written communication or a text in a first language is produced as the written communication or text in the second language interpreting the same meaning. Here the text in the first language is called "source text" and the equivalent text that communicates the same message in another language is called target text. The term "Translation" is generally defined as the action of interpretation of the meaning of the text, and production of an equivalent text that communicates the same message in another language.

According to Nida \& Taber Translation consists in reproducing in the receptor language the closest natural equivalent of the source language message, first in terms of meaning and secondly in terms of style. (Nida and Taber 1982:32)

But translation of literature is not merely a matter of finding words in one language as substitute for those of another. It is not only a matter of finding adequate literary expression of linguistic constructions corresponding to the language of the original work. In the translated version it involves more-the transfer of concepts, aesthetic, cultural, psychological and historical- from people speaking one language to those speaking another. This implies at least mastery on the part of the translator of three important placements.

i) The language of the original

ii) The Content- in its widest sense of the original work

iii) Ability to adequately render the original linguistics and contextual material into the target language

Thus translation of literary works especially poetry is not an easy task. But a good translation of literature gives us the substitute to the original works. 


\section{What is Comparative literature?}

Comparative literature is an academic field dealing with the literature of two or more different languages. While most frequently practised with work of different languages, it may also be performed on works of the same language if the work of that language originate from different nations or cultures among which that language is spoken. It also includes the comparisons with different types of arts, for example a relationship of film to literature, literature and folk/fine arts and literature and music etc. Under interdisciplinary activities we also discuss the relation of literature with other disciplines like history, philosophy, sociology and psychology etc. To understand literature in totality it is very necessary to study in comparison to other disciplines.

\section{Definitions of Comparative Literature}

\section{According to Remak (1971)}

"Comparative literature is viewed as a study of literature beyond national boundaries and it is concerned with the study of the relationship between literature and other areas of knowledge and beliefs"(Borrowed from a article"Comparative Literature"written by Ceritera hati, 29th January, 2010 http://butterflyneeraz.blogspot. $\mathrm{com} / /$ )

\section{According to Sussan Bassnett}

" comparative literature is the study of text from different culture contexts and origins to identify their points of convergence and divergence with reference to these two highly reliable and credible sources, it is best to summarise that comparative literature is basically portrayed as the study of literature beyond national boundaries that aims to highlight the relationship between literature and other areas of knowledge and belief as well as to ascertain their point of convergence and divergence. (Sussan Bassnett 1993:25)

The study of 'Cinderella' for example, is said to be 
comparative provided that it involves with two or more short stories of Cinderella written by different national boundaries and it underscores the dissimilarities and similarities shared by those literary texts. By keeping this condensed definition in mind, it is very helpful in drawing a line between what is said to be a study of comparative literature and what is not meant to be a study of comparative literature.

\section{Importance/Role of translation in Comparative Literature}

I will start my point with the help of map given below. In this map we can see that there are so many languages spoken all over the world. People from all these languages are interconnected. To understand the views, ideas, feelings and emotions of people from different parts of the world we need translation. In this era of globalization when the whole world has become a global village where a human being comes into contact with other language speaking people daily.

Map showing different languages spoken at different parts of the world

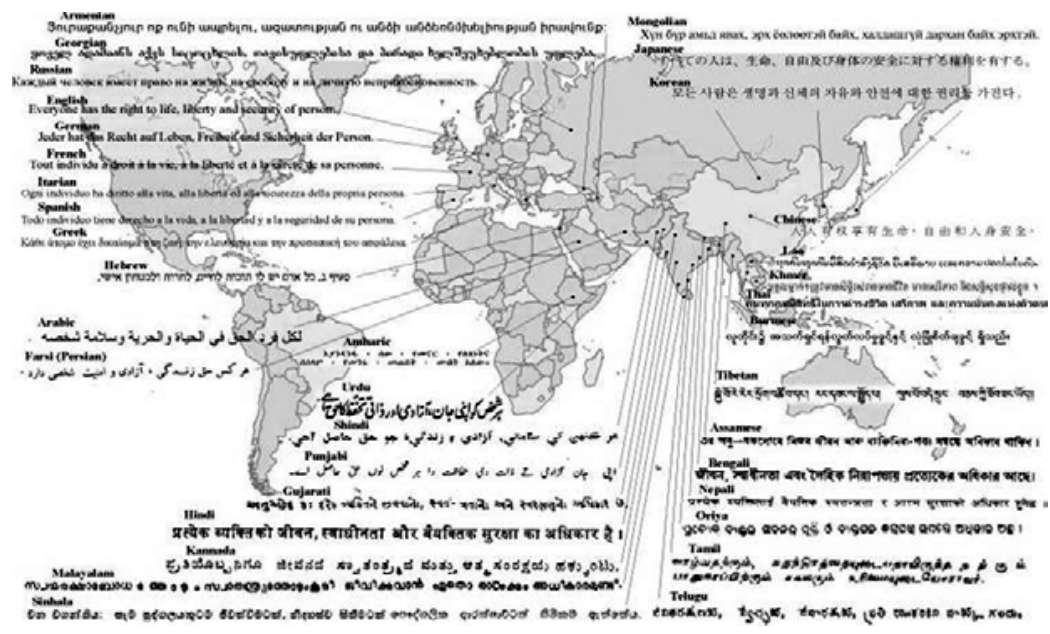


Thus we can see that there are so many languages and almost every language has its own literature, its own culture. A normal person usually not knows more than twothree languages. But if $s /$ he wanted to study and compare the literature of two or more languages s/he must be familiar with those languages and cultures. If $s /$ he does not know any of that particular languages/he can take help of translation. Those texts might be translated by someone else who knows that language and the comparativist can use that translated text to solve his/ her purpose. So we can say that:

1. Comparative literature and translation are inter-linked.

2. A layman can come closer to the major writers of different fields.

3. Through the translation of literature from different languages we can understand their philosophy, sociology, psychology and above all their culture.

4. Either translation or through comparison the problems of particular area's people will analyzed.

5. With the help of translation a text become able to get a wider range of readers.

Comparative literature is a discipline dedicated to the study of literature without national and linguistic barriers. The student of comparative literature study problems in genre, mode, literary period or movement. The comparativists probe the mechanics of literary forms and engage themselves in the analysis of existing theoretical and critical approaches and the formulation of necessary critical distinctions of equal importance. The comparativists also deal with the questions of interaction between literature and other arts and disciplines. The compartivist may study the political, social and an intellectual context of literary emphasis is preserved. In other words, the main objective 
of the study of comparative literature is the proper appreciation of literature in a larger perspective, involving more than one literature and specially those growing across the national boundaries. In a multilingual country like ours we have two basic objectives for studying comparative literature.

On the Indian literary scene, comparative literary methodology can be extremely useful in developing a concept of unified Indian literary history on a single level of organization. By Indian literary history, I mean, the history of the regional manifestations of Indian literature, giving Sanskrit its due place as a preamble to the whole structure, depicting a historically convincing graph of continuous literary emergence in terms of varying dimensions of our national experience. While a good deal of literature is produced in India, it has not yet been possible to develop the idea of a unified Indian literature since it is written in many languages. At present, in spite of individual studies of regional literatures on a broad comparative and critical scale, the idea of one Indian literature is yet to be developed in its proper perspective. Indian literature is still a mere collection of different literatures having diverse linguistic manifestations. Through comparative literary studies alone can we arrive at the oneness of Indian literature.

The other objective is to develop a fuller appreciation of western literature. Professor Buddhadeva Bose says that English being the most widespread foreign language in India, the unfortunate and incongruous situation for an ambitious student of western literature is to concentrate solely on English and know Europe exclusively through England. As a result, we imbibe British prejudices, applaud Robert Bridges and denigrate D.H. Lawrence, and do our English literature without even hearing of Baudelaire or Heine, Ovid or Dante, Whitman or the Great Russians. An obvious remedy for this is the dissemination of the knowledge of western literature other than English, and it is here that comparative literature can fulfill a genuine need of our literary pursuits. This lengthy introduction is in defense of the propagation of the study 
of comparative literature (C. L.) in india is to emphasise its role in evolving the idea of one Indian literature and understanding western literature in a more comprehensive manner . Coming to the means and methods of securing these objectives we are faced with the most important but controversial question of literary translations.

A decisive requirement for the study of Comparative Literature for achieving the aforesaid objectives is a broad knowledge of several literatures available in different language. This is an accidental fact that Indian civilization is polyglot, and has been so for centuries. The knowledge of two or more Indian languages may be an asset for a student of literature, but how many of them can one learn, particularly when we have 22 major languages? Similarly, how many foreign languages can one learn to appreciate western literature? Eventually, one will have to go for translations to study the literature of different languages.

To write a history of Indian literature with the help of comparative methodology one should know the majority of Indian languages or s/he will take the help of translation. To know the minds of great Indian writers who wrote in different Indian languages and the great writers from different foreign languages and cultures the comparativist must know their languages which is rarely possible. In this case translation becomes a very big helping hand.

No doubt knowledge of language is important, but it has no direct bearing on literary understanding .The Nobel Committee awarded the Nobel prize to Tagore on the basis of the translation of Gitanjali, of course, rendered by the poet himself. It was a translation from the original Bengali. One is free to choose between the two alternatives: the grim satisfaction of struggling through a few pages of the original or the enriching experience of racing through the author's 'inscape' in a language one can easily comprehend. The latter one is the best option for a literature student. Though $\mathrm{s} /$ he needs the knowledge of language but as 
s/he is not a student of a language school, his or her main focus should be on the content and form of the text.

There are numerous practical problems in translating literature, particularly when such translations are going to be used by readers in a different country. It is certainly not easy to appreciate a western author placing him in the historical context and evaluating him aesthetically in the broader context of English or any other western literature.

Literature being a creative work, the translation according to Henry Gifford"can never be more than an oil painting reproduced in black and white" (Henry Gifford, Comparative Literature, 1969). One more thing which we have to keep in mind is that when the creative imagination works intensely- whether in a lyric, a play or a novel - it organizes the material with a degree of subtlety and comprehensiveness that no translation may match. The unity of the completed work draws together a multitude of converging details but is bound to be impoverished in a translation.

A translation has to accept one of the two equations as the basis for his activity. One equation is $A-B=$ nearer to the original. Here ' $A$ ' indicates the original and ' $B$ ' indicates the degrees of loss. The second equation is $A-B+C=$ separated quite away from the original. Here ' $C$ ' means the things added by the translator. The translator of the literary work generally goes in for the latter. But $s /$ he must have the necessary training to keep a control on the second equation if at all s/he accepts it. This can be done by analysis of the textual material of source language (SL) and semantic analysis of referential and connotative meaning and restructuring it into equivalent textual material of target language ( $T L)$.

When the translator follow the second equation i.e. while translating the Source Language Text into Target Language Text there is always a possibility of modification in the meaning generally associated with some degree of gain and loss. In this 
process the translator's work may be good, or even great, and may even surpass the original if $\mathrm{s} / \mathrm{he}$ is a good craftsman and artist.

In fact, translations often lose sight of the fact that translation itself is an interpretation, a creative process by it mean that $s /$ he should not bother about fidelity to the original and take liberties with the author's mind at the time of creation? William Cowper says that "total fidelity is also unfaithfulness." But too many liberties with the original would also be impermissible.

The question of taking liberties or freedom in translation is sometimes raised in the name of ease and pleasure. It is argued that a translation must be such as can be read with ease and pleasure but without violating the meaning or message of the original text. The risks lie in the extent of the degree of freedom which the translator permits himself. It must be admitted that there is a distinction between the original author and the translator because of two things: one the translator has his own expression and style which is influenced both by his/her personality and by the period of history in which s/he lives. Secondly, the system of form and meaning in the source language may be similar to that in the target language, but is never the same. As a result there can be no exact translation.

We can know about the socio-cultural context of a particular author through the dimensions of language usersgeographical origin, social class and time and also through the dimensions of language use-medium (simple/complex) the social role (relationship between addresser and addressee the social attitude ( the degree of social formality as evident in the style). Thus every source text has its own socio-cultural and linguistic context. But when the translator translates a text, his/ her socio-cultural and linguistic contexts governs the process of translation and as a result we have a text not free from the impact of translator's background. 
So translation playsaveryimportantrolein thecomparative study of literature. But at the same time a comparative study of the two referential systems (the particular linguistic and cultural systems of the writer and the translator) helps us to understand the translated version of a literary text with reference to the translator's reading strategies, degree of objectivation, the extent to which the general is modified or replaced by the specific and the type of bilingualism. Comparison of seven significant English translations of Gita Govinda done by William Jones (1792) Edwin Arnold (1875), George Keats (1940), Lakshmi Narayan Shastri (1956), Duncan Greenlidge (1962), Monika Verma(1968), Barbara Stoler Miller (1977) provides not only an insight into literature but also captures the change in sensibility that marks different epochs and mood and the temperament of the translator. At the same time a comparative study of the source text having linguistic/ literary and extra- literary conventions gives an idea of the literary idiom and cultural tenor of the source text and perceives the textual profile in its proper perspective. In fact, comparative criticism in the process of analyzing translation brings close analysis of language to bear on cross-cultural literary questions in a way central to comparative literature, since a unique creative energy is generated where languages converge.

In comparative literature, the knowledge of language is important, but it has no direct bearing on literary understanding. In many cases the study of translation becomes a comparative critical exercise of great value, even for readers who lack the original. Intelligent students of literature can benefit from a systematic comparison of six significant translations in Hindi of the Rubaiyats of Omar Khayyam. All these are retranslations of the English translation by Fitzgerald. One of Persian Rubaiyats translated by Fitzgerald is:

Dreaming when Dawn's left hand was in the sky

I heard a voice within the tavern cry

Awake my little ones, and fill the cup 
Before life's liquor in its cup be dry.

Now 'my little ones ' is the translation of Khayyam's 'A Rind Kharavati' which means 'Drunkards of the tavern' 'Drunkards of the tavern' is wrongly translated as 'My little ones' and this has raised different connotative meaning in the mind of various translators according to different cultural setups in which they live. Harivanshrai Bachchan translates it as 'Mere Sishuo nadan', Keshab Pd. Pathak as 'Mera Sishudal' and Maithisharan Gupta as 'O mere Bachhe' Sumitranandan Pant has a pedagogic attitude to this term and translates it as 'Madira ke Chhatra'. Bachchan does not stop at the filling of the cup and insists other to drink it even'Bujha lo pi-pi mandira bhukh'. Maithilisharan Gupta, being a Vaishnavite, slowly utters 'Patra Bharo na Vilamba Karo', as if afraid of drinking.

A comparison of these various translations can shed light not only on the changes in a given civilization's attitude towards literature, but also on the changes in a society's attitude towards certain other topics. These culture-bound attitudes so thoroughly stylize our perceptions that we experience our 'traditionality' as natural but without going deep into the historical causes, the roots of determinism which underlie the 'recursive' structure of our sensibility and expressive codes we cannot translate properly. The cultural contexts of a given discourse could be extremely deep rooted, e.g., in 'Asadhya veena' by Agyeya the terms kesh kambali, Gufa-geha, Hatha sadhana, Kricha tapa are taken from the Buddhist Hinayana yogic terminology, indicating that communion with the ultimate in a state of selflessness may lead to spiritual accomplishment. Agyeya picks up this cultural reference to project his idea about the creative process. In his translation of this poem with the help of professor Leonard E Nathan the corresponding terms 'whose robe a rug', 'whose home was a cave in the hills', 'irresistible vow', 'disciplined devotion', could not project the cultural-bound meanings which reside in our unconscious. In the same way 'Main kanfata hun', - a line of poem 'Mein tum logo se dure hun' by Muktibodh is translated as 'I am the split-eared, 
the underground wretch' by Vishnu Khare which cannot fit with cultural milieu and as a result the cross- cultural communication becomes an impossibility.

Thus translation of a text or concept by different translators from different cultural and language backgrounds show the distance between the respective source and target language communities. Obvious differences in the unique cultural heritage of the two communities must be considered in the translation studies. This culture-bound assessment leads us near to comparative literature which is study of literature of the relationship between literatures on the one hand and other areas of knowledge and belief on the other hand. Comparative perspective looks at all literature as one organic process, a continuous and cumulative whole. That being the reason one can hope that the comparative method can be helpful in cross- cultural communication in translation. We all know that no language can exist unless it is steeped in the context of culture, so the exact translation is a hypothesis only. We all know that translation is done for a unilingual community bound by its own cultural properties. It means that any discourse in the SL and its translation in TL should be accepted as two sets of possible worlds having a 'Dynamic equivalence' (Nida). The question of equivalence is related to meaning, to be precise-pragmatic meaning. 'Equivalent' does not mean identical: the response can never be identical because of different cultural, historical and situational setting. So it is always necessary to aim at equivalence of programmatic meaning, if necessary at the expense of semantic equivalence. Pragmatics relates to the correlation between linguistic units and the user(s) of these units in a given communicative situation. We may therefore consider a translation to be primarily a pragmatic reconstruction of its source text. Only then the cross- cultural communication becomes feasible.

One can quote two translations- one in Hindi and the other in Bengali- of T.S Eliot's Ash Wednesday. In the Hindi translation by Vishnu Khare the 'formal correspondence' method 
is used. The effect of this method on the reader is unnatural and tiring because this method seeks to produce a counterpart in a receptor language whose form corresponds to the original as nearly as possible. Now for the Hindi unilingual reader the terms like'Ash Wednesday,' 'Juniper-Briksha,' 'Dhyan me Virgin ka adar karti hain', 'Mai ke Samay,' 'Bakain k phool', 'Neel Mery ke Varna ke Vastra Pahine' are foreign and indicate the cultural gap. Knowledge of these foriegn terms demands from the reader a lengthy learning process with the help of secondary literature which very few readers are prepared to undertake. How can a reader in Hindi without special knowledge understand 'Ash Wednesday' that it is the first day of Lent in the Roman Catholic, Anglican and some other churches? It is so named from the ceremonial use of ashes as a symbol of penitence in the service for the day. To cover this cultural gap, Bishnu Dey in Bengali transforms all these foreign terms into Indian terms, particularly which are familiar with the Bengali unilingual reader. As a result 'Ash Wednesday' is changed into 'Charaker Gan'- a similar kind of religious ceremony of Bengal (Man is always taking a new form by discarding the old); 'Juniper briksha' as 'jaytri Gach', 'Dhyan Me Virgin ke Adar Karti Hain' as 'Devaki mata Dhyan Karen'; 'May' is changed into 'Phalguni' , 'Bakain ke phool' as Atasi puspa'; 'Neel mery ke Verna ke Vastra Pahine' is changed into 'Sri Radhar Neelamber'.

Bishnu Dey's effort of dynamic equivalence in translation does not attempt to fill the cultural gap, rather it makes the difference between the cultures as clear as possible but by matching the communicative value of the source text with the communicative value of the target text, i.e., where both the texts are related to pragmatic meaning and in popovic's term where the invariant core of the ST is not lost, the proper result is achieved. In another poem Gerontion by Eliot, Vishnu Khare keeps the same caption in Devanagari Script, Whereas Vishnu Dey translate it as 'jarayan' in Bengali which immediately communicates the meaning to a Bengali reader. 
Besides, some of the names of persons and places which occur in the poem like Brussels, London, Mr. Silvero, Madame de Tarnquist, Fraulein von Kulp are exactly reproduced in Hindi, whereas in the Bengali version they are changed to Kanpur, Kalkatai (in Calcutta), Hatilal Mehta, Lady Mukherjee, Mister Tarafder to give an Indian or/ and bangtail colouring. We may be prone to believe that only in this way the process of communication become meaningful. In the interlingual communication, the link is the translator who is both the receptor of the original message and the source of the secondary message. Both these messages are embedded in their particular cultural frame and as a result in the cross-cultural communication there are interferences which signify difficulties that concern both the translator and the translation process. Once the translator is freed from his role as an objective mediator and keeps his receptors in mind and foresees their possible relations, conditioned by the presuppositions and the behavior patterns of their culture, only then the literary translation become possible. If the receptors are to understand a discourse bound by an alien culture then they need not only be linguistically clear reproduction, but also a minimum of information about the thought patterns and values of the source culture is to be dished out .

For this purpose the translator must make certain adaptations, as done by Bishnu Dey, but these must be minimal with an eye at equivalence of pragmatic meaning. Comparison gives us the clue to the understanding of literature as one entity having different manifestations- almost like the one ultimate Brahma having different forms of the Hindu theology. It helps us understand literature as literature in English, in Bengali, in Hindi, not as English literature, Bengali literature or Hindi literature. Thus in spite of the obvious cultural distance between English and Hindi and Bengali language communities, some kind of an equation of balance is possible in the process of translating one discourse into another. 
However, there is another point of view which is more valuable. It says that it cannot reduce a cross cultural reference to such a level where the very idea for going for translation for enjoying foreign literature with its cultural contexts becomes redundant. Bishnu Dey could have filled up the gap or the time-place-tradition elements with footnotes or he could have ignored this problem of cross-cultural references as done in Hindi translation. But it would have been ignoring the problem without solving it. Use of footnotes would have unreasonably divided the source text into parts- target text and the footnotes. And these two parts could have disturbed the autonomy of the source text. Moreover; the footnotes could have spoiled the overall structure of the source text.

Sometimes critics talk of a solution of using less unfamiliar references in place of unfamiliar references. With reference to flora, name of cities or proper personal names one could make use of this method but transferring 'Christ the tiger' into 'Elo Krishna Narashimha' is making use of completely familiar terms of the target language for conveying a meaning. Colour locale is changed here which goes well with the target language. But it may not be accepted as proper.

Regarding conveying the core meaning through the target text one may not forget that the source text in its totality manifests the core meaning and it is quite important to know how the translator picks up this meaning which is commonly known as the invariant core of the original text. Bishnu Dey transforms this invariant core or the original message by Indianising the cultural references.

To sum up I may say that it is very difficult to create the same text in the target language through translation. By using his/her creativity translator tries to reproduce the meaning/ knowledge and material of the source text into target language keeping in mind the socio-cultural preferences of the target readers. Through a translated text we become able to reach 
nearest to that point of the distance between two cultures. The job of a translation is to turn strangeness into likeness and in the process the strangeness of the original becomes more vivid but this vividness itself liberates us from the cultural person and gives us the taste of another culture.

The role of translation in comparative literature is really admirable. Translation has not only combined the countries with different languages of this global world but also it has introduced us to great poets and other writers. So translation is a main tool in the comparative study of literature. Without translation a comparativist cannot reach the world classics, texts written in different languages and without knowing or understanding these texts s/he cannot go for comparative study. In our country we see that most of the work in the field of comparative literature is bilingual i.e. it is mainly between our national language Hindi and any one of the regional languages. But after the interaction with international language, English, the area of comparative study of literature in our country becomes wider than earlier. Now we are comparing our literature with any of the foreign languages literatures. Through translation we also get familiar with literatures of other foreign languages like French, Italian, Russian, German etc. and some efforts have also been done to do a comparative study of Indian literature with literature of these languages. Realizing the importance of translation in the comparative study of literatures from different languages the Universities which offer the academic programme in Comparative Literature also introduced one paper of the theory and practice of translation.

\section{Conclusion}

No doubt the role of translation in comparative literature is very important. It becomes more valuable in today's world when the whole world has become a global village. With the advancement of technology people living in different countries with different languages come closer to each other. Although there is a one international language, English, which is the common 
source of communication between people but still there is a problem in the study of literature as literatures is usually written in regional languages or languages of that particular countries such as France's literature is in French and literature of Russia is in Russian language. It is not compulsory that every comparativist will know the all languages. So there is need of translation by which a comparativist can read and understand those literary works which are not in his/her own language. With the help of translation we become familiar with the customs, dress code, and culture of other countries.

In short it can be said that translation plays a great role in comparative literature. We can even say that comparative study of literatures from different languages, cultures and socio-cultural backgrounds is not possible without translation. So translation occupies a special place in comparative literature. In this age of globalization comparative literature as a subject is getting more and more popularity. But there is no one who is perfect in all the languages. So translation has played/plays a very important role to understand the literature \& culture of different languages without which we cannot do a comparative study of various literary works written in different languages. So comparative literature is a tree with translation as its most important branch.

\section{REFERENCES}

Apter, Emily. 2005. The Translation Zone: A new Comparative Literature, Princeton University Press.

Bassnett, Sussan. 1993. Comparative Literature: A Critical introduction, Oxford, Blackwell Publishers.

Henry Gifford. 1969. Comparative literature, London, Routledge and K. Paul.

Horst, Frenz and Newton P. Stallknecht. 1961. Comparative Literature: Method and Perspective, IlliNois, Southern Illinois University press. 
James, S. Holmes. 1970. "Literature and Translation", Katholike universiteit te Leuven.

Mueller, Kurt, Volluner and Michael Transcher (Ed.). 1998. Translating Literatures, Translating cultures: New vistas and approaches in Literary studies, Burlin, Erich Schmidt.

Nida, E.A., and taber, C.R. 1982. Theory and Practice of Translation, Boston, Brill Academic Publishers.

Popovic, A. 1975. A Dictionary for the Analysis of literary translation, Department of Comparative Literature, University of Alberta.

Totosy day Zepetnek steven. 1998. Comparative Literature: Theory, Method, Application, Atlanta, B.V. Amsterdam. 